\title{
PROMOÇÃO DA SAÚDE E AÇÕES FONOAUDIOLÓGICAS EM EDUCACÃO INFANTIL
}

\author{
Health promotion and speech and language therapy actions \\ in infantile education
}

\author{
Júlia Escalda Mendonça( ${ }^{(1)}$, Stela Maris Aguiar Lemos ${ }^{(2)}$
}

\begin{abstract}
RESUMO
Objetivos: verificar o conhecimento de educadores de uma unidade de educação infantil de Belo Horizonte a respeito do desenvolvimento da comunicação humana e seus distúrbios em crianças e as suas concepções sobre a atuação fonoaudiológica nessas instituições Método: estudo transversal desenvolvido em três etapas: Diagnóstico Institucional; Aplicação de formulário para caracterização do conhecimento das educadoras a respeito do desenvolvimento e distúrbios da comunicação humana; Planejamento e realização de oficinas. A análise da relação entre variáveis foi realizada utilizando o Teste Exato de Fisher, considerando o nível de significância de 5\% no programa estatístico Epi Info 2000, versão 3.2.2. Resultados: a maioria das educadoras respondeu corretamente às questões relacionadas ao uso e à compreensão da linguagem pela criança e às atitudes adequadas para a comunicação entre adultos e crianças. $66,7 \%$ acertaram as questões a respeito dos marcos do desenvolvimento de linguagem e 58,3\% responderam incorretamente à questão relativa ao processamento auditivo. Foram realizadas 17 oficinas com os temas "Processamento Auditivo" e "Saúde Vocal", nas 8 salas que participaram da atividade 172 alunos na faixa etária de 3 a 6 anos, 8 professoras e 4 estagiárias. Conclusões: as educadoras demonstraram conhecimentos acerca da aquisição e desenvolvimento de linguagem, dos distúrbios da comunicação humana, e da atuação do fonoaudiólogo, principalmente na perspectiva clínica e preventiva. As oficinas realizadas propiciaram a discussão da importância do desenvolvimento de ações de prevenção e promoção da saúde em Fonoaudiologia.
\end{abstract}

DESCRITORES: Saúde Pública; Promoção da Saúde; Comunicação; Educação Infantil; Desenvolvimento de Linguagem

\section{INTRODUÇÃO}

As instituições de educação infantil constituem um dos principais ambientes comunicativos das crianças e um local privilegiado para a atuação fonoaudiológica.

O Referencial Curricular Nacional para Educação Infantil prevê que as instituições de

(1) Fonoaudióloga graduada pela Universidade Federal de Minas Gerais; Mestre em Música pela Universidade Federal de Minas Gerais.

(2) Fonoaudióloga; Professora Adjunto do Departamento de Fonoaudiologia da Universidade Federal de Minas Gerais; Doutora em Ciências pela Universidade Federal de São Paulo.

Conflito de interesses: inexistente educação infantil devem abranger além de seu papel educativo, o desenvolvimento integral da criança ${ }^{1}$. O fonoaudiólogo tem papel importante no desenvolvimento infantil na medida em que contribui para a criação de ambientes favoráveis ao desenvolvimento das habilidades comunicativas humanas. Entretanto, para que isso seja possível, é necessário ampliar suas formas de atuação em instituições de educação infantil para além das ações preventivas tradicionais.

Nessa perspectiva, a atuação fonoaudiológica nessas instituições deve ser fundamentada em conceitos e diretrizes que visem enfrentar os problemas de saúde por meio de ações coletivas e contribuir com a melhoria da qualidade de vida da população. 
A promoção da saúde é uma estratégia promissora para enfrentar os múltiplos problemas de saúde que afetam as populações humanas e seus entornos ${ }^{2}$. Assumir o paradigma da saúde e sua promoção implica em buscar outras estratégias para a ação fonoaudiológica, que incorporem características dialógica, reflexiva, participante e problematizadora, as quais possibilitem aos sujeitos identificar e analisar os determinantes de suas condições de vida e saúde e que ofereçam alternativas para controlá-las melhorando e transformando a sua realidade ${ }^{3,4}$.

A literatura mostra que procedimentos de avaliações, triagens e encaminhamentos no sistema educacional não se mostraram meios eficazes de prevenção de alterações da comunicação ${ }^{5}$. Além disso, o trabalho fonoaudiológico deve ser elaborado de acordo com as características da comunidade $^{6}$. Neste contexto a literatura mostra também que práticas vinculadas à realidade da população envolvida e com enfoque na promoção da saúde devem ser realizadas, como por exemplo ações fonoaudiológicas pautadas no diagnóstico situacional que permite identificar espaços potenciais de ação e oficinas são importantes métodos de trabalho por facilitar a criação de vínculos e a interação entre os participantes ${ }^{7}$.

Cabe ressaltar também, que a perspectiva da promoção da saúde é uma possibilidade para a orientação da práxis fonoaudiológica e que o campo de trabalho e pesquisa relativo ao eixo da saúde pública e coletiva é um espaço privilegiado para o encontro da Fonoaudiologia com a realidade de vida da população ${ }^{8}$.

Atualmente, a escola é considerada local estratégico para a construção de comunidades com melhores condições de qualidade de vida. Contudo, a literatura mostra que os educadores têm conhecimentos sobre promoção da saúde, mas precisam de capacitação e apoio para atuar como agentes promotores de saúde $e^{9,10}$.

O presente estudo justifica-se pela importância de um trabalho fonoaudiológico voltado para ações coletivas e intersetoriais, que integrem as áreas de saúde e educação, na construção coletiva do saber, capacitação de educadores e sua formação em agentes multiplicadores de ações promotoras da saúde em Fonoaudiologia.

\section{Objetivos}

1. verificar o conhecimento de educadores de uma unidade de educação infantil de Belo Horizonte a respeito do desenvolvimento da comunicação humana e seus distúrbios em crianças e as suas concepções sobre a atuação fonoaudiológica nessas instituições;
2. verificar as relações entre o tempo de formação, o tempo de trabalho na educação e o conhecimento das profissionais da educação a respeito dos temas acima descritos;

3. descrever e discutir os achados de oficinas desenvolvidas em uma unidade de educação infantil buscando ampliar o conhecimento de professores/educadores sobre assuntos relacionados ao campo fonoaudiológico.

\section{MÉTODO}

Trata-se de estudo descritivo com amostra de conveniência realizado em uma Unidade Municipal de Educação Infantil (UMEI) de Belo Horizonte. O estudo foi realizado em três etapas, a saber:

Primeira etapa - Diagnóstico Institucional: Foi realizada entrevista com uma das funcionárias da equipe pedagógica da UMEI a fim de caracterizar os recursos físicos, materiais, humanos e do plano pedagógico da instituição. A entrevista foi norteada pelo roteiro utilizado no Programa Creche do Curso de Fonoaudiologia da Faculdade de Medicina da Universidade de São Paulo ${ }^{11}$ que contém questões sobre a identificação da creche, recursos humanos, recursos físicos, população atendida, linha pedagógica e atendimento à família.

Segunda etapa - Coleta de dados: Foi realizada adaptação para o estudo um formulário proposto pela literatura ${ }^{12}$ por meio da inclusão de questões acerca das condutas frente a dificuldades de comunicação e do aprimoramento de habilidades comunicativas (Figura 6). $\mathrm{O}$ instrumento foi composto por questões abertas e fechadas que visavam caracterizar conhecimento das professoras, educadoras e estagiárias da Unidade Municipal de Educação Infantil a respeito da aquisição, desenvolvimento e distúrbios da comunicação humana. A abordagem dos sujeitos da pesquisa ocorreu em uma reunião agendada com a coordenação pedagógica da instituição. Neste momento, antes do início da coleta de dados, foram apresentados os objetivos, métodos e cronograma da pesquisa e esclarecidas dúvidas elencadas pelas educadoras e estagiárias. Foi realizada a aplicação dos formulários às professoras, educadoras e estagiárias que concordaram em participar do estudo. Os questionários foram aplicados de acordo com o horário livre de cada grupo de três professoras da Unidade Municipal de Educação Infantil.

Terceira etapa - Planejamento e realização de oficinas: Baseado nos achados das entrevistas foram planejadas e executadas oficinas de promoção da saúde. Os temas selecionados, "Audição e Processamento Auditivo" e "Saúde Vocal", levaram em consideração a demanda elencada pelas 
educadoras e estagiárias no momento da reunião e da coleta de dados da segunda etapa.

Houve preparação prévia das educadoras para realização das oficinas por meio de reuniões com uma das pesquisadoras e apresentação de uma apostila, contendo bases teóricas sobre os assuntos abordados nas oficinas e esclarecimentos sobre objetivos, duração e descrição das atividades a serem desenvolvidas. As oficinas foram realizadas em salas de aulas e as educadoras atuaram como facilitadoras em parceria com a pesquisadora que conduziu o processo.

Os critérios de inclusão e exclusão que definiram a casuística deste estudo são:

- Critérios de Inclusão: Ser educador, professor ou estagiário na UMEl; ter lido, concordado e assinado o Termo de Consentimento Livre e Esclarecido e ter respondido o formulário na íntegra

- Critérios de Exclusão: Estar impossibilitado de exercer suas funções por qualquer motivo no período de realização do trabalho, como por exemplo, estar em licença das atividades no momento da coleta de dados.

O presente estudo foi submetido à avaliação e teve a aprovação do Comitê de Ética em Pesquisa da Universidade Federal de Minas Gerais sob o número ETIC 082/05.

Os dados coletados foram analisados segundo os enfoques quantitativo e qualitativo.

Foi realizada análise descritiva das respostas apresentadas às questões fechadas do formulário, considerando-se de maneira distinta as 10 questões com apenas uma alternativa de resposta das 4 questões com mais de uma possibilidade de resposta. Foram utilizadas tabelas de freqüências para as variáveis categóricas e visualização gráfica dos principais achados. A análise da relação entre as variáveis: tempo de formação e tempo de trabalho na educação e respostas encontradas no formulário foi realizada utilizando o Teste Exato de Fisher. Foi considerado o nível de significância de $5 \%(0,05)$ em todas as análises.
A análise de dados das questões abertas e do caderno de campo das oficinas realizadas foi fundamentada na Análise de Conteúdo, de tal modo que as idéias centrais das respostas de uma mesma questão foram identificadas para posterior comparação do grupo e síntese do conhecimento geral. Após a seleção das categorias a serem analisadas em cada questão, verificou-se a sua freqüência de ocorrência (aparecimento) nos discursos dos sujeitos.

A entrada, o processamento e a análise quantitativa dos dados foram realizados por meio do programa EPI-INFO, versão 3.4 (2007).

\section{RESULTADOS}

A amostra de entrevistados foi composta por: cinco professoras, três educadoras e quatro estagiárias, todas do sexo feminino. A idade variou entre 18 e 56 anos, sendo a idade média 34 e a mediana de 32 .

Das professoras e educadoras, seis possuíam o ensino superior completo e duas pós-graduações. Dessas, 2 (17\%) cursaram Letras, 4 (25\%) cursaram Pedagogia, 1 (8\%) cursou Psicopedagogia e 1 (8\%) cursou Serviço Social. Das estagiárias, 2 (17\%) cursam o ensino médio e $2(17 \%)$ cursam o ensino normal superior.

O tempo de formação das professoras e educadoras variou entre 2 e 19 anos, sendo 3 formadas entre 2 e 5 anos (25\%), 4 formadas entre 6 e 10 anos (33,5\%) e 1 formada há mais de 10 anos $(8 \%)$. As $4(33,5 \%)$ estagiárias encontravam-se em formação.

O tempo de trabalho com a educação das professoras e educadoras, e estagiárias variou entre 1 e 24 anos, sendo que $5(42 \%)$ trabalham na educação entre 1 e 5 anos, $3(25 \%)$ trabalham na educação entre 6 e 10 anos e 4 (33\%) trabalham há mais de 10 anos na educação.

$\mathrm{Na}$ tabela 1 estão os dados referentes às questões com apenas uma resposta correta. 
Tabela 1 - Distribuição das respostas encontradas nas questões relativas a aquisição e desenvolvimento da linguagem e comunicação na infância

\begin{tabular}{|c|c|c|c|c|c|c|}
\hline \multirow{2}{*}{ Questão 1} & \multicolumn{2}{|c|}{ Professoras e Educadoras } & \multicolumn{2}{|c|}{ Estagiárias } & \multicolumn{2}{|c|}{ Total } \\
\hline & $\mathbf{N}$ & $\%$ & $\mathbf{N}$ & $\%$ & $\mathbf{N}$ & $\%$ \\
\hline Correta & 8 & 66,7 & 3 & 25,0 & 11 & 91,7 \\
\hline Incorreta & 0 & 0,0 & 1 & 8,3 & 1 & 8,3 \\
\hline TOTAL & 8 & 66,7 & 4 & 33,3 & 12 & 100,0 \\
\hline \multirow{2}{*}{ Questão 3} & \multicolumn{2}{|c|}{ Professoras e Educadoras } & \multicolumn{2}{|c|}{ Estagiárias } & \multicolumn{2}{|c|}{ Total } \\
\hline & $\mathbf{N}$ & $\%$ & $\mathbf{N}$ & $\%$ & $\mathbf{N}$ & $\%$ \\
\hline Correta & 6 & 50,0 & 2 & $16,7^{*}$ & 8 & 66,7 \\
\hline Incorreta & 2 & $16,7^{*}$ & 2 & $16,7^{*}$ & 4 & 33,3 \\
\hline TOTAL & 8 & 66,7 & 4 & 33,3 & 12 & 100,0 \\
\hline \multirow{2}{*}{ Questão 4} & \multicolumn{2}{|c|}{ Professoras e Educadoras } & \multicolumn{2}{|c|}{ Estagiárias } & \multicolumn{2}{|c|}{ Total } \\
\hline & $\mathbf{N}$ & $\%$ & $\mathbf{N}$ & $\%$ & $\mathbf{N}$ & $\%$ \\
\hline Correta & 8 & 66,7 & 3 & 25,0 & 11 & 91,7 \\
\hline Incorreta & 0 & 0,0 & 1 & 8,3 & 1 & 8,3 \\
\hline TOTAL & 8 & 66,7 & 4 & 33,3 & 12 & 100,0 \\
\hline \multirow{2}{*}{ Questão 5} & \multicolumn{2}{|c|}{ Professoras e Educadoras } & \multicolumn{2}{|c|}{ Estagiárias } & \multicolumn{2}{|c|}{ Total } \\
\hline & $\mathbf{N}$ & $\%$ & $\mathbf{N}$ & $\%$ & $\mathbf{N}$ & $\%$ \\
\hline Correta & 7 & 58,4 & 1 & 8,3 & 8 & 66,7 \\
\hline Incorreta & 1 & 8,3 & 3 & 25,0 & 4 & 33,3 \\
\hline TOTAL & 8 & 66,7 & 4 & 33,3 & 12 & 100,0 \\
\hline \multirow{2}{*}{ Questão 6} & \multicolumn{2}{|c|}{ Professoras e Educadoras } & \multicolumn{2}{|c|}{ Estagiárias } & \multicolumn{2}{|c|}{ Total } \\
\hline & $\mathbf{N}$ & $\%$ & $\mathbf{N}$ & $\%$ & $\mathbf{N}$ & $\%$ \\
\hline Correta & 8 & 66,7 & 3 & 25,0 & 11 & 91,7 \\
\hline Incorreta & 0 & 0,0 & 1 & 8,3 & 1 & 8,3 \\
\hline TOTAL & 8 & 66,7 & 4 & 33,3 & 12 & 100,0 \\
\hline \multirow{2}{*}{ Questão 8} & \multicolumn{2}{|c|}{ Professoras e Educadoras } & \multicolumn{2}{|c|}{ Estagiárias } & & \\
\hline & $\mathbf{N}$ & $\%$ & $\mathbf{N}$ & $\%$ & $\mathbf{N}$ & $\%$ \\
\hline Correta & 4 & $33,3^{*}$ & 3 & 25,00 & 7 & 58,3 \\
\hline Incorreta & 4 & $33,3^{*}$ & 1 & 8,3 & 5 & $41,7^{*}$ \\
\hline TOTAL & 8 & 66,7 & 4 & 33,3 & 12 & 100,0 \\
\hline Ouectว̃ก 9 & Profes: & Icadoras & & ias & & \\
\hline Questad & $\mathbf{N}$ & $\%$ & $\mathbf{N}$ & $\%$ & $\mathbf{N}$ & $\%$ \\
\hline Correta & 6 & 50,0 & 1 & 8,3 & 7 & 58,3 \\
\hline Incorreta & 2 & 16,7 & 3 & 25,0 & 5 & 41,7 \\
\hline TOTAL & 8 & 66,7 & 4 & 33,3 & 12 & 100,0 \\
\hline Questão 10 & Profes: & Icadoras & & ias & & \\
\hline Questao 10 & $\mathbf{N}$ & $\%$ & $\mathbf{N}$ & $\%$ & $\mathbf{N}$ & $\%$ \\
\hline Correta & 3 & 25,0 & 2 & $16,7^{*}$ & 5 & 41,7 \\
\hline Incorreta & 5 & 41,7 & 2 & $16,7^{*}$ & 7 & 58,3 \\
\hline TOTAL & 8 & 66,7 & 4 & 33,3 & 12 & 100,0 \\
\hline Questão 14 & Profes: & Icadoras & & ias & & \\
\hline Questav 14 & $\mathbf{N}$ & $\%$ & $\mathbf{N}$ & $\%$ & $\mathbf{N}$ & $\%$ \\
\hline Correta & 8 & 66,7 & 3 & 25,0 & 11 & 91,7 \\
\hline Incorreta & 0 & 0,0 & 1 & 8,3 & 1 & 8,3 \\
\hline TOTAL & 8 & 66,7 & 4 & 33,3 & 12 & 100,0 \\
\hline
\end{tabular}

* Trata-se de arredondamento automático: dízima periódica. 
$\mathrm{Na}$ tabela 2 encontram-se descritos os resultados das questões com mais de uma alternativa de resposta, vale esclarecer que foram consideradas corretas as questões em que somente as alternativas corretas foram assinaladas. Foram consideradas parcialmente corretas as questões em que alternativas corretas e alternativas incorretas foram assinaladas. Foram consideradas incorretas as questões em que somente as alternativas incorretas foram assinaladas.

Tabela 2 - Distribuição das respostas encontradas nas questões com mais de uma possibilidade de respostas relativas ao desenvolvimento comunicativo na infância

\begin{tabular}{|c|c|c|c|c|c|c|}
\hline \multirow{2}{*}{ Questão 7} & \multicolumn{2}{|c|}{ Professoras e Educadoras } & \multicolumn{2}{|c|}{ Estagiárias } & \multicolumn{2}{|c|}{ Total } \\
\hline & $\mathbf{N}$ & $\%$ & $\mathbf{N}$ & $\%$ & $\mathbf{N}$ & $\%$ \\
\hline Correta & 4 & $33,3^{*}$ & 0 & 0,0 & 4 & 33,3 \\
\hline Incorreta & 0 & 0,0 & 1 & 8,3 & 1 & 8,3 \\
\hline Parcialmente Correta & 4 & $33,3^{*}$ & 3 & 25,0 & 7 & 58,3 \\
\hline TOTAL & 8 & 66,7 & 4 & 33,3 & 12 & 100,00 \\
\hline \multirow{2}{*}{ Questão 11} & \multicolumn{2}{|c|}{ Professoras e Educadoras } & \multicolumn{2}{|c|}{ Estagiárias } & \multicolumn{2}{|c|}{ Total } \\
\hline & $\mathbf{N}$ & $\%$ & $\mathbf{N}$ & $\%$ & $\mathbf{N}$ & $\%$ \\
\hline Correta & 2 & 16,7 & 2 & $16,7^{\star}$ & 4 & 33,3 \\
\hline Incorreta & 5 & 41,7 & 2 & $16,7^{*}$ & 7 & 58,3 \\
\hline Parcialmente Correta & 1 & 8,3 & 0 & 0,0 & 1 & 8,3 \\
\hline TOTAL & 8 & 66,7 & 4 & 33,3 & 12 & 100,00 \\
\hline \multirow{2}{*}{ Questão 12} & \multicolumn{2}{|c|}{ Professoras e Educadoras } & \multicolumn{2}{|c|}{ Estagiárias } & \multicolumn{2}{|c|}{ Total } \\
\hline & $\mathbf{N}$ & $\%$ & $\mathbf{N}$ & $\%$ & $\mathbf{N}$ & $\%$ \\
\hline Correta & 1 & 8,3 & 0 & 0,0 & 1 & 8,3 \\
\hline Incorreta & 0 & 0,0 & 0 & 0,0 & 0 & 0,0 \\
\hline Parcialmente Correta & 7 & 58,4 & 4 & 33,3 & 11 & 91,7 \\
\hline TOTAL & 8 & 66,7 & 4 & 33,3 & 12 & 100,0 \\
\hline \multirow{2}{*}{ Questão 13} & \multicolumn{2}{|c|}{ Professoras e Educadoras } & \multicolumn{2}{|c|}{ Estagiárias } & \multicolumn{2}{|c|}{ Total } \\
\hline & $\mathbf{N}$ & $\%$ & $\mathbf{N}$ & $\%$ & $\mathbf{N}$ & $\%$ \\
\hline Correta & 5 & 41,7 & 1 & 8,3 & 6 & 50,0 \\
\hline Incorreta & 0 & 0,0 & 0 & 0,0 & 0 & 0,0 \\
\hline Parcialmente Correta & 3 & 25,0 & 3 & 25,0 & 6 & 50,0 \\
\hline TOTAL & 8 & 66,7 & 4 & 33,3 & 12 & 100 \\
\hline
\end{tabular}

Ao analisar as respostas relativas aos profissionais aos quais encaminhar crianças que não falam, verificou-se que o fonoaudiólogo foi citado 11 vezes, sendo o profissional mais citado $(91,7 \%)$, seguido pelo médico, citado 5 vezes $(41,7 \%)$. O psicólogo, neurologista e o otorrinolaringologista também foram citados com duas e uma citações respectivamente.

As formas de atuação do fonoaudiólogo na UMEI segundo professoras e estagiárias foram analisadas e verificou-se que a maioria delas atribui ao fonoaudiólogo a função de realizar diagnóstico e detectar problemas de fala, voz e audição.(figura 1).
Nos quadros 1 e 2 estão descritos os resultados referentes a associação entre tempo de formação e de docência ao acerto das questões referentes a comunicação humana e desenvolvimento infantil.

Baseado nos resultados das questões e nas as referências consultadas sobre desenvolvimento comunicativo infantil, foram realizadas 17 oficinas, 9 com o tema Processamento Auditivo e $8 \mathrm{com}$ o tema Voz, nas 8 turmas que participaram deste estudo. Participaram das oficinas 172 crianças, 8 professoras e educadoras e 4 estagiárias. (tabela 3)

As figuras 4 e 5 apresentam o compilado as atividades desenvolvidas e resultados obtidos nas oficinas realizadas. 


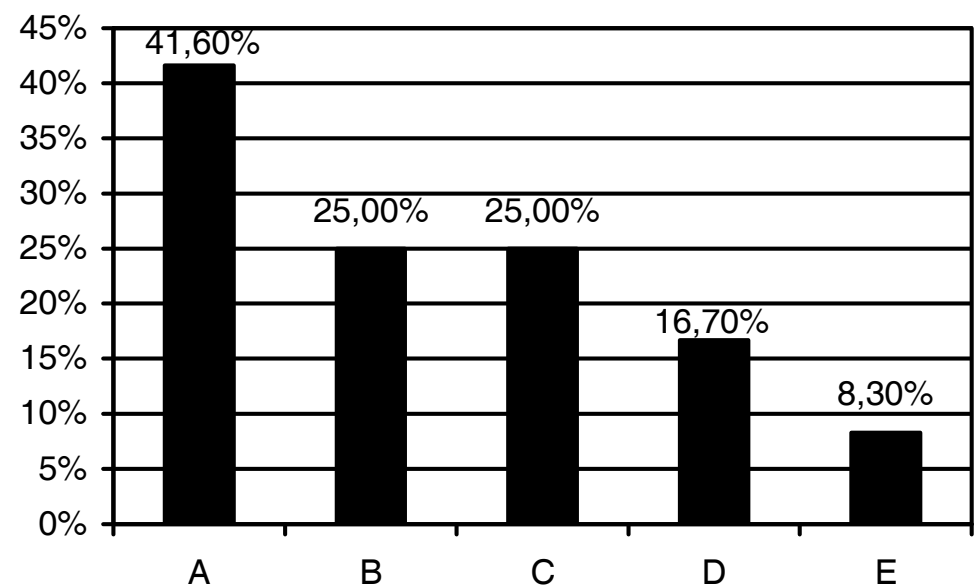

A - Fazer diagnóstico / detectar problemas; B - Fazer intervenção com as crianças; - Orientar os professores da UMEI; D - Apoiar os professores da UMEI; E - Trabalhar em parceria com os professores da UMEI

Teste Exato de Fisher

$\mathrm{P}=$ pvalor obtido no estudo da correlação

Figura 1 - Gráfico demonstrativo da freqüência das respostas encontradas na questão relativa às formas de atuação do fonoaudiólogo na UMEI

\begin{tabular}{|c|c|c|c|c|c|c|c|c|c|}
\hline \multirow{2}{*}{$\begin{array}{l}\text { Tempo de } \\
\text { formado }\end{array}$} & \multicolumn{9}{|c|}{ Questão } \\
\hline & 1 & 2 & 3 & 5 & 6 & 8 & 9 & 10 & 14 \\
\hline $\begin{array}{l}0 \text { a } 5 \\
\text { anos }\end{array}$ & $p=0,75$ & $p=0,75$ & $\mathrm{p}=0,25$ & $\mathrm{p}=0,25$ & $p=0,75$ & $p=0,36$ & $p=0,16$ & $p=0,16$ & $p=0,75$ \\
\hline $\begin{array}{c}6 \text { a } 10 \\
\text { anos }\end{array}$ & $p=0,66$ & $p=0,33$ & $p=0,40$ & $p=0,59$ & $p=0,66$ & $p=0,42$ & $p=0,57$ & $p=0,15$ & $p=0,66$ \\
\hline $\begin{array}{l}>10 \\
\text { anos }\end{array}$ & $p=0,92$ & $p=0,92$ & $p=0,66$ & $p=0,66$ & $p=0,92$ & $p=0,42$ & $p=0,58$ & $p=0,58$ & $p=0,91$ \\
\hline
\end{tabular}

Teste Exato de Fisher

$\mathrm{P}=$ pvalor obtido no estudo da correlação

Figura 2 - Estudo da Significância da comparação entre o tempo de formação das professoras, educadoras e estagiárias e as respostas dadas às questões do formulário

\begin{tabular}{|c|c|c|c|c|c|c|c|c|c|}
\hline \multirow{2}{*}{$\begin{array}{l}\text { Tempo de } \\
\text { docência }\end{array}$} & \multicolumn{9}{|c|}{ Questão } \\
\hline & 1 & 2 & 3 & 5 & 6 & 8 & 9 & 10 & 14 \\
\hline $\begin{array}{l}0 \text { a } 5 \\
\text { anos }\end{array}$ & $p=0,41$ & $p=0,58$ & $p=0,58$ & $p=0,15$ & $p=0,41$ & $p=0,24$ & $p=0,31$ & $p=0,68$ & $p=0,41$ \\
\hline $\begin{array}{c}6 \text { a } 10 \\
\text { Anos }\end{array}$ & $p=0,75$ & $p=0,75$ & $p=0,74$ & $p=0,75$ & $p=0,75$ & $p=0,45$ & $p=0,15$ & $p=0,63$ & $p=0,75$ \\
\hline $\begin{array}{l}>10 \\
\text { anos }\end{array}$ & $p=0,66$ & $p=0,33$ & $p=0,59$ & $p=0,14$ & $p=0,66$ & $p=0,42$ & $p=0,57$ & $p=0,57$ & $p=0,66$ \\
\hline
\end{tabular}

Figura 3 - Significância da comparação entre o tempo de trabalho na educação e as respostas dadas às questões do formulário 
Tabela 3 - Distribuição dos alunos participantes das oficinas por idade e sexo

\begin{tabular}{ccccccc}
\hline \multirow{2}{*}{ Idade (anos) } & \multicolumn{9}{c}{ Sexos } \\
\cline { 2 - 7 } & \multicolumn{2}{c}{ Masculino } & \multicolumn{2}{c}{ Feminino } & \multicolumn{2}{c}{ Total } \\
\cline { 2 - 7 } & $\mathbf{N}$ & $\%$ & $\mathbf{N}$ & $\%$ & $\mathbf{N}$ & $\%$ \\
\hline $3 \mid-4$ & 22 & 12,8 & 22 & 12,8 & 44 & 25,6 \\
$4 \mid-5$ & 27 & 15,7 & 25 & 14,5 & 52 & 30,2 \\
$5|-| 6$ & 38 & 22,1 & 38 & 22,1 & 76 & 44,2 \\
\hline TOTAL & 87 & 50,6 & 85 & 49,4 & 172 & 100 \\
\hline
\end{tabular}

N - Número

\begin{tabular}{|c|c|c|}
\hline \multirow[b]{2}{*}{ Temas abordados } & \multicolumn{2}{|c|}{ Resultados } \\
\hline & $\begin{array}{c}\text { Impressão das educadoras e } \\
\text { professoras }\end{array}$ & Participação dos alunos \\
\hline $\begin{array}{l}\text { Localização sonora } \\
\text { Figura-fundo para sons não } \\
\text { verbais }\end{array}$ & $\begin{array}{l}\text { Consideraram a atividade de fácil } \\
\text { reprodução e assimilação pelos alunos } \\
\text { uma vez que tem os mesmos princípios } \\
\text { da atividade lúdica "Cabra - cega" que } \\
\text { faz parte do cotidiano das crianças. }\end{array}$ & $\begin{array}{l}\text { A atividade foi realizada com sucesso } \\
\text { nas turmas em que foi desenvolvida. }\end{array}$ \\
\hline $\begin{array}{l}\text { Discriminação sonora } \\
\text { Ordenação Temporal } \\
\text { simples } \\
\text { Ordenação de padrões de } \\
\text { Freqüência e Duração }\end{array}$ & $\begin{array}{c}\text { As professoras responsáveis por turmas } \\
\text { de } 3 \text { e } 4 \text { anos consideraram a atividade } \\
\text { interessante, porém mais difícil de ser } \\
\text { assimilada pelos alunos por pressupor } \\
\text { maior organização e atenção dos } \\
\text { alunos. } \\
\text { Já as responsáveis por turmas de } 5 \text { a } 6 \\
\text { anos não observaram dificuldades na } \\
\text { realização das mesmas. Entretanto } \\
\text { todas as professoras e educadoras } \\
\text { consideraram a atividade de fácil } \\
\text { reprodução. }\end{array}$ & $\begin{array}{c}\text { Todos os alunos colaboraram com a } \\
\text { realização das atividades. Ainda assim, } \\
\text { nas turmas de } 4 \text { a } 5 \text { anos as atividades } \\
\text { foram desenvolvidas em período maior } \\
\text { que o previsto para a oficina. } \\
\text { Em uma das turmas dessa faixa etária a } \\
\text { oficina não pode ser concluída pela } \\
\text { dificuldade de compreensão e } \\
\text { desatenção dos alunos. } \\
\text { Nas turmas de } 5 \text { a } 6 \text { anos os alunos } \\
\text { cumpriram as tarefas no tempo previsto } \\
\text { para a oficina e não houve dificuldades } \\
\text { por parte das crianças. }\end{array}$ \\
\hline
\end{tabular}

Figura 4 - quadro demonstrativo dos Temas abordados, e resultados das oficinas de audição (processamento auditivo) segundo relato dos participantes e observação das pesquisadoras

\begin{tabular}{|c|c|c|}
\hline \multirow[b]{2}{*}{ Temas Abordados } & \multicolumn{2}{|c|}{ Resultados } \\
\hline & $\begin{array}{c}\text { Impressão das educadoras e } \\
\text { professoras }\end{array}$ & Participação dos alunos \\
\hline $\begin{array}{l}\text { Conceito de Voz } \\
\qquad \text { e } \\
\text { Produção vocal }\end{array}$ & $\begin{array}{l}\text { As professoras sentiram-se } \\
\text { contempladas com os assuntos } \\
\text { abordados, pois consideram que os } \\
\text { alunos gritam muito, que há muita } \\
\text { competição sonora. Consideraram as } \\
\text { atividades relevantes para a sua própria }\end{array}$ & $\begin{array}{c}\text { Os alunos participaram respondendo às } \\
\text { perguntas e fazendo a vivência proposta. } \\
\text { A atividade foi realizada com sucesso nas } \\
\text { turmas em que foi desenvolvida. }\end{array}$ \\
\hline Uso saudável da voz & $\begin{array}{c}\text { Todas as professoras, educadoras e } \\
\text { estagiárias consideraram as atividades } \\
\text { de fácil reprodução uma vez que } \\
\text { demandam conceitos básicos de } \\
\text { produção e saúde vocal que elas } \\
\text { passaram a dominar e } \\
\text { a mediação de histórias é prática diária } \\
\text { em sala de aula. }\end{array}$ & $\begin{array}{c}\text { Os alunos interessaram-se pela história, } \\
\text { colaboraram com a realização das } \\
\text { atividades. } \\
\text { Em todas as turmas as atividades foram } \\
\text { desenvolvidas no período previsto para a } \\
\text { oficina e não houve dificuldades por parte } \\
\text { das crianças. }\end{array}$ \\
\hline
\end{tabular}

Figura 5 - quadro demonstrativo dos Temas abordados, e resultados das oficinas de Voz (saúde vocal) segundo relato dos participantes e observação das pesquisadoras 


\section{Formulário adaptado para coleta de dados}

\section{Dados:}

Idade: Sexo: Nível de escolaridade:

Curso realizado: Tempo de formado:

Tempo que leciona: Série que leciona:

1. Aos 6 ou 8 meses os bebês balbuciam alguns sons, este balbucio não influencia na preparação da linguagem falada. Esta afirmação é:
( ) verdadeira
( ) falsa

2. Dos 9 ou 10 meses os bebês têm uma linguagem gestual combinada com sons, o que faz parte do desenvolvimento normal. Isso contribui para o aparecimento das primeiras palavras?
( ) $\operatorname{sim}$
( ) não

3. A primeira palavra acontece entre os 12 aos 15 meses?
( ) $\operatorname{sim}$
( ) não

4. As crianças não compreendem a fala antes de serem capazes de falar. Essa afirmação é:
( ) verdadeira
( ) falsa

5. Aos 3 anos a fala é fluente, mais extensa, mais complexa e algumas crianças muitas vezes omitem partes de fala. De acordo com esta afirmativa podemos concluir que as crianças:

( ) conseguem comunicar bem o que desejam

( ) não conseguem comunicar bem o que desejam

( ) nesta idade ainda não têm intenção comunicativa

6. Uma criança que não fala aos 3 anos pode ter perda auditiva?
( ) $\operatorname{sim}$
( ) não

7. Deve-se ter suspeita de surdez quando:

( ) não move a cabeça em direção ao barulho

( ) tem choro descontrolado

( ) acorda com barulhos intensos

( ) não tem interesse por barulho

( ) não ri

( ) adquire fala e linguagem em comparação com os padrões esperados

( ) não faz acentuado uso de gesto

( ) apresenta / demonstra desatenção

( ) não tem necessidade de aumentar o volume do rádio e da televisão

8. Aos 3 ou 4 anos, as crianças são capazes de formar frases notavelmente complexas. Mais tarde, surgem as habilidades mais refinadas, como aprender a usar frases na voz passiva.
( ) $\operatorname{sim}$
( ) não

9. Crianças com idade entre dois anos e meio e cinco anos podem apresentar disfluência na fala. Isso pode ser entendido como uma patologia?
( ) $\operatorname{sim}$
( ) não

10. Entre 4 e 5 anos as frases das crianças têm em média 4 ou 5 palavras,elas usam preposições como sobre, sob, em e atrás?

( ) $\operatorname{sim}$

( ) não 
11. Para uma criança reconhecer e compreender a fala ela não precisa ser capaz de:

( ) prestar atenção

( ) detectar, discriminar e localizar sons

( ) memorizar e integrar as experiências auditivas

( ) brincar com funcionalidade

12. Quando falamos com uma criança devemos:

( ) procurar posições mais estratégicas como estar de frente para ela

( ) falar em seu lugar

( ) verificar se a criança interage com você

( ) observar se a criança mantém contato de olhos

( ) nomear sistematicamente objetos e ações

( ) solicitar sempre suas capacidades ou exigir acima do que ela pode responder para estimulá-la

13. O que podemos fazer para aprimorar as capacidades de linguagem da criança?

( ) aguardar observar, ouvir tudo o que a criança tem para manifestar: gestos, vocalizações e olhares;

( ) testar as capacidades das crianças com ordens e perguntas

( ) usar linguagem compatível com as possibilidades de compreensão pela criança

( ) fornecer oportunidades que favoreçam a comunicação e saber aguardar uma resposta

( ) dirigir a ação da criança dizendo como ela deve agir ou proceder

( ) interromper os silêncios que correspondem ao tempo de espera que se deve dar para que a criança tome a iniciativa de comunicação

( ) não atuar de forma diretiva e controladora, dando oportunidades para a criança manifestar seus desejos, interesses e necessidades

14. A estimulação por meio da leitura de história para as crianças é parte essencial do sucesso do desenvolvimento da linguagem escrita, permite à criança internalizar as diferentes estruturas entre linguagem escrita e a oral. Essa afirmação é:

( ) verdadeira

( ) falsa

15. Quando a criança não fala, quais os primeiros profissionais para os quais ela deve ser encaminhada?

16. É importante ter um fonoaudiólogo que auxilie a equipe da unidade de educação infantil?
() $\operatorname{sim}$
( ) não

Por quê?

Figura 6 - Formulário utilizado para coleta de dados

\section{DISCUSSÃO}

Ao analisar as repostas dadas pelas professoras, educadoras e estagiárias às questões relativas ao desenvolvimento de fala e linguagem, verificouse que mais de $90 \%$ responderam corretamente àquelas relacionadas à influência do balbucio na linguagem falada; à utilização da linguagem oral e gestual; à compreensão da linguagem pela criança $e$ à importância da leitura de histórias para o desenvolvimento comunicativo infantil. Esses dados indicam que essas profissionais têm conhecimentos sobre tais temas, e são capazes de perceber aspectos relevantes ao uso da linguagem por crianças. Não foram encontradas pesquisas na literatura que corroborassem os achados do presente estudo.

As questões referentes à ocorrência da primeira palavra, e ao comportamento comunicativo de crianças de 3 anos, e a elaboração frasal, também foram respondidas corretamente pela maioria das entrevistadas, porém com menor porcentagem de acertos (de 58 a $67 \%$ de acertos). Tais achados demonstram que, embora mais da metade das educadoras tenham respondido adequadamente as questões, ainda existe uma parcela importante que apresenta dúvidas sobre o tema pesquisado o que mostra a necessidade de se discutir e buscar construir conjuntamente com essas profissionais, 
conhecimentos sobre tais temas a fim de capacitálas a reconhecer aspectos do desenvolvimento normal da linguagem das crianças

Em relação às disfluências comuns presentes na fala de crianças, os resultados deste estudo aproximam-se da literatura que demonstrou que professores apresentam dificuldades em reconhecer $e$ podem identificar erroneamente a gagueira e que faltam informações sobre esse tema para esse grupo de profissionais. Os autores encontraram interesse dos professores em ampliar seus conhecimentos sobre a gagueira ${ }^{13,14}$. É importante ressaltar que o uso do termo disfluência no instrumento de coleta de dados provocou dúvidas na maioria das professoras, educadoras e estagiárias o que pode ter provocado um número maior de erros.

A análise da questão relativa ao uso de preposições por crianças de quatro a cinco anos indicou que a maior parte dessas profissionais não observa tal aspecto do desenvolvimento da linguagem de crianças. Deste modo, evidencia-se a necessidade de considerar os aspectos do desenvolvimento sintático como eixo temático a ser discutido com as profissionais entrevistadas.

Pode-se atribuir os resultados encontrados no presente estudo ao fato de os profissionais da educação terem maior facilidade em perceber marcos relevantes do desenvolvimento comunicativo infantil, entretanto, percebe-se que essas profissionais atêm-se, sobretudo, aos aspectos pragmáticos da linguagem em detrimento dos aspectos sintáticos e gramaticais. Isso significa que essas profissionais são capazes de identificar as alterações da comunicação, relacionadas aos grandes marcos do desenvolvimento comunicativo, o que corrobora com parte da literatura ao demonstrar que professores são eficientes na identificação de alterações da comunicação em crianças 5 .

Sendo assim, crianças com alterações comunicativas leves ou menos evidentes serão encaminhadas tardiamente, ou não serão encaminhadas ao atendimento fonoaudiológico corroborando com estudos que demonstraram a falta de conhecimentos de educadores sobre prevenção e alterações da comunicação ${ }^{6}$.

$\mathrm{Na}$ literatura consultada foram encontrados diversos estudos ${ }^{11,16-20}$ que demonstraram a importância da instrumentalização de educadores e a participação do fonoaudiólogo em atividades de planejamento buscando facilitar o encaminhamento de crianças de risco para alterações comunicativas ou ampliar ações de promoção da saúde fonoaudiológicas nestes espaços.

A concepção das professoras e estagiárias sobre os indícios de perda auditiva em crianças revelou que as professoras e estagiárias conhecem e identificam alguns indícios para surdez em crianças, mas que também possuem concepções inadequadas sobre esse assunto. Contudo, a análise do conhecimento dos professores sobre as habilidades auditivas envolvidas no reconhecimento e compreensão de fala por crianças revelou que mais da metade das entrevistadas respondeu incorretamente a essa questão. $O$ resultado mostra que o processamento auditivo não é de conhecimento das professoras, educadoras e estagiárias, contudo vale ressaltar que este é um conhecimento relativamente recente no campo da Fonoaudiologia.

Nota-se que a audição é um aspecto da comunicação humana que não é de domínio dos entrevistados. Esse dado é relevante na medida em que as habilidades auditivas estão associadas ao processo de aquisição e desenvolvimento de comunicação e ao aprendizado da leitura e da escrita. Os resultados corroboram com os achados de estudos que demonstram que professores desconhecem as desordens do Processamento Auditivo, mas são importantes na identificação de alunos com distúrbios auditivos e que demonstraram a falta de orientação e de conhecimento específico sobre saúde auditiva de crianças por professores ${ }^{21,22}$. Os dados revelaram que as educadoras, professoras e estagiárias conhecem, identificam e adotam posturas adequadas na relação comunicativa com crianças, o que corrobora a literatura que investigaram as posturas adotadas por professores aos distúrbios da comunicação de seus alunos ${ }^{23}$.

A alta ocorrência de citações do fonoaudiólogo como o profissional a quem se devem encaminhar as crianças demonstrou que as professoras, educadoras e estagiárias têm conhecimento a respeito do trabalho do fonoaudiólogo. Contudo, outros estudos descreveram o desconhecimento de profissionais da educação a respeito do trabalho fonoaudiológico e sua área de atuação ${ }^{6,23-25}$. Nos achados do presente estudo, a maioria das professoras citou mais de um profissional responsável pelo atendimento à criança que não fala, o que revela que essas profissionais consideram o trabalho interdisciplinar importante para o tratamento dos distúrbios da comunicação. Esses resultados estão de acordo com a literatura que verificou que professores consideram que o tratamento da gagueira deve ocorrer por meio da equipe multidisciplinar ${ }^{14}$.

As formas de atuação do fonoaudiólogo na UMEI, segundo professoras e estagiárias, revelaram que na concepção dos professores o fonoaudiólogo deve atuar na instituição de educação infantil realizando trabalho caracteristicamente clínico, voltado para o diagnóstico e intervenção. Esses resultados estão de acordo com a literatura uma vez que foi demonstrado que professores atribuem mais importância 
à ação curativa do que à ação preventiva ${ }^{26}$. Essa concepção das educadoras estagiárias a respeito do trabalho fonoaudiológico pode ser justificada pelas práticas históricas dos fonoaudiólogos nas instituições de ensino, marcadamente baseadas no modelo clínico, voltadas para atendimentos individuais e a ação curativa realizada na escola ${ }^{16}$. Esses achados também estão de acordo com estudos nos quais educadores atribuíram as ações de promoção da saúde aos profissionais e serviços de saúde e acreditavam que a atuação do fonoaudiólogo na creche deve ter um caráter clínico-terapêutico ${ }^{12,27}$.

Não foi observada relação entre o tempo de formação, o tempo de trabalho na educação e os conhecimentos da amostra sobre a temática abordada no presente estudo.

Em relação as oficinas frente às habilidades auditivas trabalhadas, verificou-se, segundo anotações do caderno de campo das pesquisadoras que nenhuma professora ou educadora referiu realizar qualquer atividade relacionada à saúde auditiva de seus alunos. Em relação aos alunos, as atividades de saúde auditiva propostas nas oficinas foram realizadas com sucesso por todos os alunos das turmas participantes.

A respeito das atividades de saúde vocal, todas as professoras e educadoras relataram ter tido contato prévio com fonoaudiólogos por meio de palestras e ter sido orientadas sobre o uso da voz. Entretanto, nenhuma delas referiu realizar atividades de saúde vocal com os alunos. Em relação aos alunos, todos se interessaram e participaram das atividades de saúde vocal propostas nas oficinas.Tais resultados são indicativos da necessidade e possibilidade da realização deste tipo de atividade em instituições de educação infantil como demonstram outros estudos ${ }^{10,28}$.

No presente estudo optou-se em utilizar a realização de oficinas considerando-se a literatura que aponta que esta estratégia é um importante método de trabalho por se constituir em um processo educativo de mudanças que facilitam a formação de vínculos e possibilitam a percepção dos sujeitos sociais capazes de transformar a realidade em que vivem e são uma opção metodológica para a promoção da saúde ${ }^{7,29-31}$.

Os resultados deste estudo apontam para a importância das atividades de promoção da saúde fazerem parte do planejamento pedagógico de instituições de educação infantil.

Cabe ressaltar que o trabalho em conjunto com as professoras e educadoras, pautada na prática da educação em saúde fornece instrumentos a tais profissionais para que possam identificar as causas e consequências dos problemas de saúde em relação com suas práticas diárias além de adotar soluções específicas em nível individual e coletivo e ainda favorece a construção de vínculo entre a Fonoaudiologia e a Educação ${ }^{29-32}$. A literatura enfatiza a importância da formação de educadores voltada para a promoção da saúde da interação entre educadores e crianças ${ }^{33,34}$ e que professores necessitam de capacitação e apoio para atuar como agentes promotores de saúde ${ }^{9,35}$.

Assim sendo, é de fundamental importância o aprofundamento da relação dos setores da saúde e da educação por meio de ações fonoaudiológicas voltadas a criação e manutenção de ambientes favoráveis à saúde que visem práticas preventivas e promotoras da saúde. A partir do momento em que duas áreas, saúde e educação, dialogarem é possível buscar espaços intersetoriais em suas práticas profissionais que propiciem o desenvolvimento conjunto dessas ações ${ }^{36}$. .

As ações desenvolvidas neste estudo pautaramse no diagnóstico situacional da instituição e na demanda das educadoras, na capacitação de recursos humanos e no privilégio das ações grupais e evidenciaram a importância da realização de ações voltadas para a realidade local e envolvimento dos sujeitos. Deste modo, no planejamento das oficinas foi privilegiada a discussão do eixo audição / processamento auditivo eliciou muitas dúvidas nas entrevistadas e o eixo voz a pedido da equipe técnica e educadoras da creche.

No presente estudo, a discussão de aspectos da comunicação humana e o mapeamento do conhecimento de educadoras sobre a temática, podem ser considerados relevantes e podem, ainda contribuir no avanço na investigação na área de promoção da saúde e Fonoaudiologia. Apesar das contribuições do estudo, foram observadas algumas limitações durante a sua realização. Duas delas foram o tamanho e o delineamento da amostra, visto que foi utilizado como campo de estudo apenas uma instituição de ensino. Além disso, a amostra de conveniência e pequena impede generalizações dos achados. Outra limitação, diz respeito ao instrumento utilizado na coleta de dados, embora tenha sido possível levantar temáticas fundamentais na discussão do desenvolvimento comunicativo de crianças, algumas questões podem ter gerado fatores de confusão em parte dos entrevistados. $O$ fato de o instrumento ter sido aplicado sob forma de entrevista pode ter minimizado tais dificuldades, pois frente as dúvidas dos entrevistados a pesquisadora explicava a terminologia utilizada.Desse modo, acredita-se que é importante realizar uma nova adaptação do instrumento para utilização em futuros estudos, incluindo aplicação de um piloto e a ampliação do tamanho da amostra a ser estudada. 
De todo modo discutir os achados dos presentes estudo remete ao fato de que o trabalho da Fonoaudiologia em instituições de educação infantil, tomando por referência os pressupostos da promoção da saúde, é um desafio constituído pela busca de ações fonoaudiológicas pautadas na qualidade de vida, educação permanente e saúde da comunicação humana em lugar de marcadores preventivistas, delineados pela doença.

\section{CONCLUSÕES}

Diante dos resultados encontrados pode-se concluir que:

1. Os profissionais da educação entrevistados demonstraram conhecimentos de aspectos da comunicação humana e são capazes de perceber aspectos relevantes a respeito da aquisição e desenvolvimento de linguagem e dos distúrbios da comunicação humana. Os aspectos pragmáticos da linguagem são percebidos com maior facilidade por essas profissionais em detrimento aos aspectos sintáticos e gramaticais. A audição, e especificamente o processamento auditivo, foram aspectos da comunicação humana menos conhecidos por essas profissionais.

2. Não foi observada relação entre o tempo de formação, o tempo de trabalho na educação e os conhecimentos da amostra sobre tais assuntos.

3. As oficinas realizadas propiciaram a discussão da importância do desenvolvimento de ações de prevenção e promoção da saúde em Fonoaudiologia, e buscaram a interface dos conhecimentos da saúde e educação na construção do saber e permitiram às profissionais da educação autonomia para incorporá-las em suas práticas diárias contribuindo, ainda que superficialmente, para a implementação de atividades de promoção da saúde em Fonoaudiologia no cotidiano da instituição.

\section{ABSTRACT}

Purpose: to check the knowledge of educators from a kindergarten unit of Belo Horizonte regarding the development of human communication and its disorders in children and their conceptions about the performance of speech therapy in these institutions. Method: the study was developed in three stages: Institutional Diagnosis; Data collection using an adapted form in order to characterize the knowledge of education professionals about the acquisition and development of human communication and its disturbances; Planning and accomplishment of workshops. The analysis of the relation between variables was carried through the Fisher Exact Test, considering the level of significance of $5 \%$ in the statistical. Results: the majority of the professionals answered correctly the questions related to the use and understanding of the language by children and related to the attitudes adjusted for communication among adults and children. $66.7 \%$ answered correctly to the questions on language development. 17 workshops benefiting 172 students aged from 3 to 6 year old and 12 education professionals were carried out. Conclusions: education professionals do not have much knowledge regarding the acquisition and development of human communication and its disturbs. Education professionals know about the work performed by the Speech and Language Therapist, but they see it from a clinical and preventive perspective. The workshops enabled the discussion of the importance of developing prevention and health promotion in Speech and Language Therapy.

KEYWORDS: Public Health; Health Promotion; Communication; Child Rearing; Language Development

\section{REFERÊNCIAS}

1. Lima ABR, Bhering E. Um estudo sobre creches como ambiente de desenvolvimento. Cad Pesquisa. 2006; 36(129):573-96.

2. Buss PM, Carvalho Al. Desenvolvimento da promoção da saúde no Brasil nos últimos vinte anos
(1988-2008). Ciênc. saúde coletiva. 2009;14(6): 2305-16.

3. Penteado RZ. Escolas promotoras de saúde - implicações para a ação fonoaudiológica. Rev Fonoaudiol Brasil. 2002; 2(1):28-37.

4. Gonçalves FD, Catrib AMF.Vieira NFC, Vieira LJES. A promoção da saúde na educação infantil. Interface. 2008;12(24):181-92. 
5. Simões JM, Assencio-Ferreira VJ. Avaliação de aspectos da intervenção fonoaudiológica junto a um sistema educacional. Rev CEFAC . 2002;4(2):97-104.

6. Caldana ML, Felício CM. Caracterização das condições e fatores de riscos para a comunicação em uma creche da cidade de Ribeirão Preto. In: Marchezan I, Zorzi J. Tópicos em Fonoaudiologia. Ed Revinter; 2003. p. 167-73.

7. Marin CR, ChunRYS, Silva RC, Fedosse E, Leonelli BS. Promoção da saúde em Fonoaudiologia: ações coletivas em equipamentos de saúde e educação. Rev Soc Bras Fonoaudiol. 2003; 8(1):35-41.

8. Penteado RZ, Servilha EAM. Fonoaudiologia em saúde pública/coletiva: compreendendo prevenção e o paradigma da promoção da saúde. Distúrb comun. 2004;16(1):107-16.

9. Luzardo R, Nemr K. Instrumentalização fonoaudiológica para professores da educação infantil. Rev CEFAC. 2006;8(3):289-300.

10. Martins J, Veríssimo MLOR. Conhecimentos e práticas de trabalhadoras de creches municipais relativos ao cuidado da criança com infecção respiratória aguda. Interface: Comunic saude educ. 2006;10(20):487-504.

11. Bitar ML. A construção da relação fonoaudiólogo - creche. In: Befi-Lopes DM. Fonoaudiologia na atenção primária à saúde. Ed Lovise; 1997. p. 101-17.

12. Cruz VMC, Neto ICO, Paolucci JF, Lemos SMA. Fonoaudiologia e creche: uma proposta de educação para a saúde. In: XII Congresso de Iniciação Científica; 2004; São Paulo. Anais. São Paulo: UNIFESP; 2004. p. 117.

13. Chiquetto MM. Reflexões sobre a gagueira: concepções e atitudes dos professores. Pró-Fono. 1996;8(1):13-8.

14. Calais LL, Jorge TM, Pinheiro-Crenitte PA. Conhecimento dos professores do ensino fundamental sobre a gagueira. Pró-Fono. 2002;14(1):23-30.

15. Giroto CRM. O professor na atuação Fonoaudiológica em escola: participante ou mero espectador? In: Giroto CRM,. Perspectivas atuais da Fonoaudiologia na escola. Ed Plexus; 1999. p. $25-41$.

16. Silva DRC, Santos LM, Lemos SMA, Carvalho SASC, Perin RM. Conhecimentos e práticas de professores de educação infantil sobre crianças com alterações auditivas. Rev. soc. bras. fonoaudiol. 2010. 15(2) : 197-205.

17. Santos JN, Lemos SMA, Rates SPM, Lamounier JA. Anemia em crianças de uma creche pública e as repercussões sobre o desenvolvimento de linguagem. Rev Paul Pediatr. 2009; 27(1):67-73.
18. Tedesco MLF, Ferraz NM, Silva RA. Triagem auditiva em crianças que freqüentam creches. In: Lagrotta MGM, César CPHAR . A Fonoaudiologia nas instituições. Ed Lovise; 1997. p 151-7.

19. Pedro AC, Ortega DA, Guadix JV, Cavalcante KR, Silva LM, Tavernaro PCS, et al. Atuação fonoaudiológica em creche. Folha Médica. 2002;121(1):38-9.

20. Lima MCMP, Barbarini GC, Gagliardo HGRG, Arnais MAO e Gonçalves VMG. Observação do desenvolvimento de linguagem e funções auditiva e visual em lactentes. Rev Saúde pública. 2004;38(1):106-12.

21. Aita ADC, Mesquita CDS, Campo CM, Fukuda $\mathrm{MTH}$, Aita FS. Correlação entre as desordens do processamento auditivo central e queixas e dificuldades escolares. J. Bras. Fonoaudiol. 2003;4(15):101-7.

22. Rissi VLF, Rocha VF, Ribeiro FL, Frota A. Promoção de saúde auditiva na perspectiva de professores da educação infantil. Rev Olho mágico. 2005;12(2):59-60.

23. Limissuri RCA, Befi-Lopes DM. Fonologia e vocabulário na percepção de educadoras sobre comunicação de pré-escolares. R. bras. Est. Pedag. 2009; 90 (225):433-48.

24. Ramos AS, Alves LM. A fonoaudiologia na relação entre escolas regulares de ensino fundamental e escolas de educação especial no processo de inclusão. Rev. bras. educ. espec. 2008(2): 235-50.

25. Maranhao PCS, Pinto SMPC, Pedruzzi CM. Fonoaudiologia e educação infantil: uma parceria necessária. Rev. CEFAC. 2009;1(1):59-66.

26. Boruchovitch E, Felix-Sousa IC, Schall VT. Conceito de doença e preservação da saúde de população de professores e escolares de primeiro grau. Rev. Saúde pública. 1991;25(6):418-25.

27. MARANHAO DG, Sarti CA. Cuidado compartilhado: negociações entre famílias e profissionais em uma creche. Interface. 2007;11(22):257-70.

28. Mendes KB, Pereira CM, Barboza EDA, Vital FA, Bezerra R, Souza MMA. A inserção do lúdico em atividades de educação em saúde na crecheescola Casa da Criança em Petrolina-PE. REVASF. 2010; 1(1):39-49.

29. Santos JN, Lemos SMA, Rates SPM, Lamounier JA. Habilidades auditivas e desenvolvimento de linguagem em crianças. Pró-Fono. 2008; 20(4):255-60.

30. Maranhao PCS, Pinto SMPC, Pedruzzi CM. Fonoaudiologia e educação infantil: uma parceria necessária. Rev. CEFAC. 2009; 11(1): 59-66. 
31. Pizzani L, Bello SF, Silva RC, Piumbato MC, Hayash IHCRM. Um estudo bibliométrico da produção científica: a interface entre a educação especial e afonoaudiologia nas bases de dados da Biblioteca Virtual em Saúde (BVS) .Distúrb Comun, 2008; 20(2): 205-18.

32. Simões-Zenari M, Latorre MRDO. Mudanças em comportamentos relacionados com o uso da voz após intervenção fonoaudiológica junto a educadoras de creche. Pró-Fono. 2008;20(1):61-6. 33. Rossetto-Ferreira MC,Amorim KS, Oliveira ZMR. Olhando a criança e seus outros: uma trajetória de pesquisa em educação infantil. Psicol. USP .2009; 20(3):437-64.
34. Sperandio AMG, Souza TF, Breno E, Mendes LC, Pereira ARS, Machado AC, et al. A Universidade colaborando na construção de um projeto de promoção da saúde: relato de experiência de um grupo de alunos de Medicina da Unicamp, Campinas, SP, Brasil. Rev bras educ. med. 2006;30(6):200-8.

35. Alves RCP, Veríssimo, MDLOR. Os educadores de creche e o conflito entre cuidar e educar. Rev bras crescimento desenvolv hum. 2007;17(1):13-25. 36. Biscegli TS, Polis LB, Santos LM, Vicentin M. Avaliação do estado nutricional e do desenvolvimento neuropsicomotor em crianças frequentadoras de creche. Rev. Paulista de Pediatria 2007; 24(4): 323-9.

Endereço para correspondência:

Departamento de Fonoaudiologia,

Faculdade de Medicina - UFMG

Stela Maris Aguiar Lemos

Avenida Alfredo Balena, 190, sala 069

Santa Efigênia

Belo Horizonte - Minas Gerais

CEP: 30130-100

E-mail: smarislemos@medicina.ufmg.br 